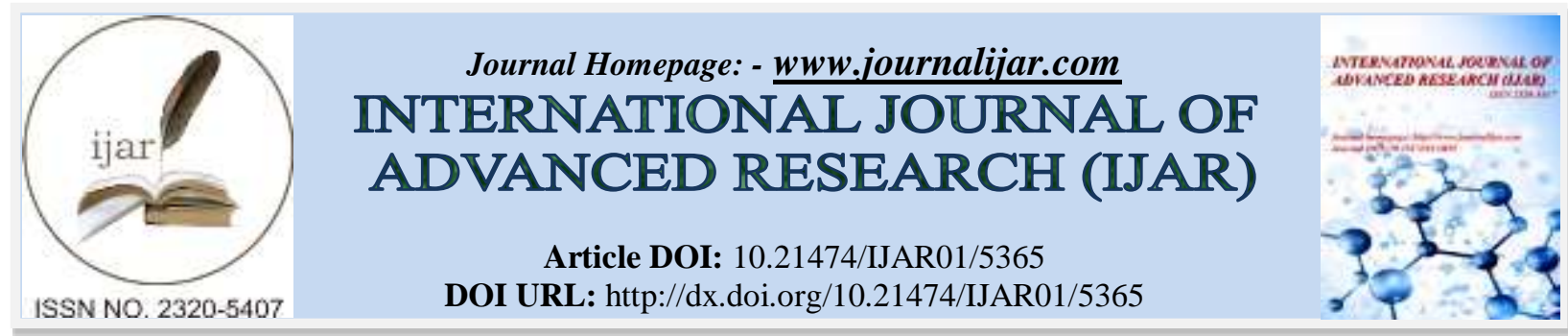

RESEARCH ARTICLE

\title{
EXPERIMENTAL INVESTIGATION OF BIO-DIESEL PRODUCTION USING PUNGAMIA OIL AND PROCESS PARAMETER OPTIMIZATION USING TAGUCHI TECHNIQUE.
}

Dr. M. Shanmugaraja ${ }^{1}$ and T. Tharoon ${ }^{2}$.

1. Professor, Department of Automobile Engineering, SNS College of Technology, Coimbatore-641035.

2. Project Assistant, Department of Mechanical Engineering, Coimbatore Institute of Engineering and Technology, Coimbatore-641109.

\section{Manuscript Info}

Manuscript History

Received: 08 July 2017

Final Accepted: 10 August 2017

Published: September 2017

Key words:-

Pungamia

TransesteriFication

Taguchi

Bio-Diesel

ANOVA

Yield.

\section{Abstract}

Background: Energy is prime mover of the all growing country. Consumption of fossil fuel has increased day by day for the reason the industrial growth and rapid increase in vehicular population, and demand for energy is increasing at very fast rate. The accelerating and frequently fluctuating price of conventional diesel has sparked renewed attention on the search for an alternative fuel

Material and Method: Biodiesel is an alternative fuel made from renewable biological sources such as vegetable oils both edible and non-edible oil and animal fat. Producing biodiesel using edible oil is not cost-effective in India. Jatropha, Pungamia, Mahua, Sal, Neem etc. are widely available non-edible oil seeds in India using which the biodiesel can be produced economically. Among them, Pungamia has a potential to be used as a basic feedstock for the production of biodiesel. Transesterification, Pyrolysis, Microemulsion and Blending are the primary methods used nowadays to produce biodiesel from non-edible sources. This paper focuses on production of biodiesel from Pungamia oil using Transesterification process and also an attempt has been made to optimize the process parameters that affect the yield of biodiesel from the oil. The process temperature, molar ratio of alcohol to the oil, types of catalyst and its concentration and reaction time are the primary parameters considered in this paper for optimization to obtain better yield using Taguchi approach.

Result: In regression equation, the goodness of fit is clarified by the determination coefficient $\left(\mathrm{R}^{2}\right)$. In this study, the value of determination coefficient is 0.962 which is indicated that $4.8 \%$ of the total variations are not explained by the regression model. The adjusted determination coefficient is 0.959 . The permutation of process parameters such as Catalyst and time have greatest contribution on response. The percentage of contribution of catalyst and time on yield is $32 \%$ and $42 \%$ respectively.

Conclusion: The percentage of errors is obtained between the predicted results and the experimental results. Errors are normally distributed and has been found that the deviation is well within the limit of $95 \%$ confidence level. It can be noted that increasing the methanol-oil ratio from 5:1 wt $\%$ to $15: 1 \mathrm{wt} \%$ had an insignificant effect on the yield. 


\section{Introduction:-}

Energy is prime mover of the all growing country. It is the most important resource to forward a country on a way to improve of economics, industrial and social development, consumption of fossil fuel has increased day by day for the reason the industrial growth and rapid increase in vehicular population, and demand for energy is increasing at very fast rate. Internal combustion engines are widely used for various applications due to their higher efficiency and compact size. The accelerating and frequently fluctuating price of conventional diesel has sparked renewed attention on the search for an alternative fuel. Biodiesel is an alternative fuel made from renewable biological sources such as vegetable oils both edible and non-edible oil and animal fat. It is derived from triglycerides by transesterification and from the fatty acids by transesterification has attracted considerable attention during the past decade as a renewable, biodegradable, eco-friendly and non-toxic fuel. Several processes for biodiesel fuel production have been developed like emulsification, pyrolysis but transesterification is commonly used commercial process to produce clean and environment friendly fuel. Biodiesels such as rapeseed biodiesel, soy bean biodiesel, sunflower biodiesel, Jatropha biodiesel, Karanja biodiesel, rice bran oil, neem oil, sal seed oil, cotton seed oil, palm seed oil, rape seed oil, castor oil, rubber seed oil are some of the biodiesel currently considered as substitute for diesel. The performance, combustion and emission characteristics of a variable compression ratio engine using cerium oxide nanoparticles and carbon nanotubes as fuel-borne nanoparticles additives in diesterol (dieselbiodiesel-ethanol) blends was investigated. The Cerium Oxide nanoparticles were an oxygen donating catalyst which provides oxygen for the oxidation of carbon monoxide and absorbs oxygen for the reduction of nitrogen oxides. The activation energy of Cerium Oxide was to burn off carbon deposits and helps to prevent the deposition of non-polar compounds on the cylinder wall resulted in significant reduction of hydrocarbon and smoke emissions ${ }^{1}$. The effect of cerium oxide nanoparticles on the performance and emission characteristics of a CI engine was studied. The ceria acts as an oxygen donating catalyst and provides oxygen for the oxidation of $\mathrm{CO}$ and/or absorbs oxygen for the reduction of NOx. Therefore, nano-particles can function as both catalyst and an energy carrier when used in base fuels in diesel engines ${ }^{2}$. The effects of addition of zinc oxide nano particles in palm oil biodiesel and the results indicate that there was increase in BTE, NOx, EGT and decrease in emissions of $\mathrm{CO}, \mathrm{HC}$ and smoke ${ }^{3}$. The effect of carbon nanotube (CNT) into diesel to achieve better performance and reduced emission was studied.The experiment were conducted on single cylinder four stroke water-cooled DI diesel engine with an electrical loading device at constant speed of 1500 RPM using neat diesel and CNT blended diesel without any modification in engine. It was observed that magnitude of emission characteristics such as $\mathrm{NO}_{\mathrm{X}}, \mathrm{CO}, \mathrm{HC}, \mathrm{EGT}$ and smoke opacity is comparatively less compared to neat diesel ${ }^{4}$. The experiments was conducted on a single cylinder diesel engine for evaluation of diesel doped with metal additives $\mathrm{MnO}$. Brake thermal efficiency was increased and the exhaust emission measurements for the fuel with manganese additive showed that CO is reduced by $37 \%$ due to higher carbon activation ${ }^{5}$. The burning characteristics, engine performance and emission parameters of a single- cylinder Compression Ignition engine using nano fuels which were formulated by sonicating nano particles of aluminum (Al) having 30-60nm, iron (Fe) 5-150 nm and boron (Bo) $80-100 \mathrm{~nm}$ in size in base diesel with $0.5 \mathrm{wt} \%$ and $0.1 \mathrm{wt} \%$ Span 80 as a surfactant for stable suspension. At higher loads, the emission study showed a decline of $25-40 \%$ in CO (vol. \%), along with a drop of $8 \%$ and $4 \%$ in hydrocarbon emissions for A1 and Fe nano fuels respectively. Due to elevated temperatures a hike of 5\% and $3 \%$ was observed in NOx emission with $\mathrm{A} 1$ and $\mathrm{Fe}^{6-7}$. The addition of $\mathrm{TiO}_{2}$ nanoparticles with diesel fuel in compression ignition engine was conducted. The addition of $\mathrm{TiO}_{2}$ nanoparticles enhances higher carbon combustion activation, act as oxygen buffer and hence promotes complete combustion. Due to the complete combustion of fuel, emissions such as CO and HC are appreciably reduced ${ }^{8-9}$. The performance, emission and combustion characteristics of single cylinder direct injection diesel engine using Neem oil biodiesel with nano additive $\mathrm{CeO} 2$ shows brake thermal efficiency for nano particles blended BN20 is higher than that of BN20 and diesel fuels and the harmful gases like, CO, HC, smoke and NOx emissions reduce significantly due to the addition of nano additive in the BN20 fuel blend. The cerium oxide additive influences the better combustion process which yields the peak pressure and heat release rate than $\mathrm{BN} 20$ and diesel fuel blends ${ }^{10}$. The combustion of aluminum nanofluid into diesel was investigated. An ultrasonicator was used to produce emulsified nano-aluminum liquid. It was observed using nano-aluminum diesel $(\mathrm{AN}+\mathrm{D})$ fuel had lowered the BSFC compared with diesel D fuel. The aluminum nanopowder additive mixed in D fuel causes a clear smoke reduction for engine speed less than 1800 RPM and NOx concentration was showing a decreasing trend ${ }^{11}$. The effect of cerium nanoparticles on the major physical properties of the biodiesel was studied. Addition of nanoparticles increases the fluid layer resistance and results in the increase of viscosity of the fuel blend. The cerium oxide nanoparticles present in the fuel blend promotes complete combustion compared to the 
base fuel and increases the fuel efficiency ${ }^{12}$. The zinc oxide nano additive added to diesel shows the ignition delay reduced, peak pressure and heat release rate increased due the presence of particles. Due to these observation, and we found that the brake thermal efficiency increased minutely. As a drawback, it was also found that the emissions NOx, increased ${ }^{13}$. The role of Zinc oxide $(\mathrm{ZnO})$ nanoparticles on the performance of single cylinder four stroke vertical water cooled diesel engine was studied. The results showed that the thermal efficiency is $35.82 \%$ only at full load for diesel fuel (DF), whereas $36.8 \%$ and $37.35 \%$ was obtained for $\mathrm{DF}+\mathrm{ZnO}$ (250 ppm) and $\mathrm{DF}+\mathrm{ZnO}(500 \mathrm{ppm})$ respectively ${ }^{14-15}$. The single cylinder direct injection diesel engine and the performance and exhaust emissions of the engine were also studied for the different blends of Kapok methyl ester. The exhaust gas temperature and specific fuel consumption are increased for rich blends of Kapok methyl ester, but the brake thermal efficiency is decreased for the same blends. The NOx emission is higher than that of diesel at all load conditions of the engine. The CO emission and smoke density are reduced for the lean blends B20 and B40 of Kapok biodiesel for all the load conditions. Similarly, the HC emission is also low for the same blends ${ }^{16}$. The test was performed on a four cylinder, compression ignition engine, operating at $2200 \mathrm{rpm}$. A water based Ferrofluid was added to diesel fuel to explore the effects on the engine exhaust emission. Results formulated on basis of load variation, which shows that adding $0.4 \%$ ferrofluid to diesel fuel decreased NOx emission by 9 to $15 \mathrm{ppm}$, adding $0.8 \%$ Ferrofluid to diesel fuel decreased NOx emission by 14 to $24 \mathrm{ppm}^{17}$. Based on the literature review concluded in this reaserch has reveadled that studied about conventional method of biodiesel production, Catalyst chemical and physical composition, Absorbed about tranestrification process, Studied about optimization technics in taquchi method,Behavioural of metal oxide in blending with B20 and conventional fuels,Performance analysis in CI engine.

\section{Proposed Methodology:-}

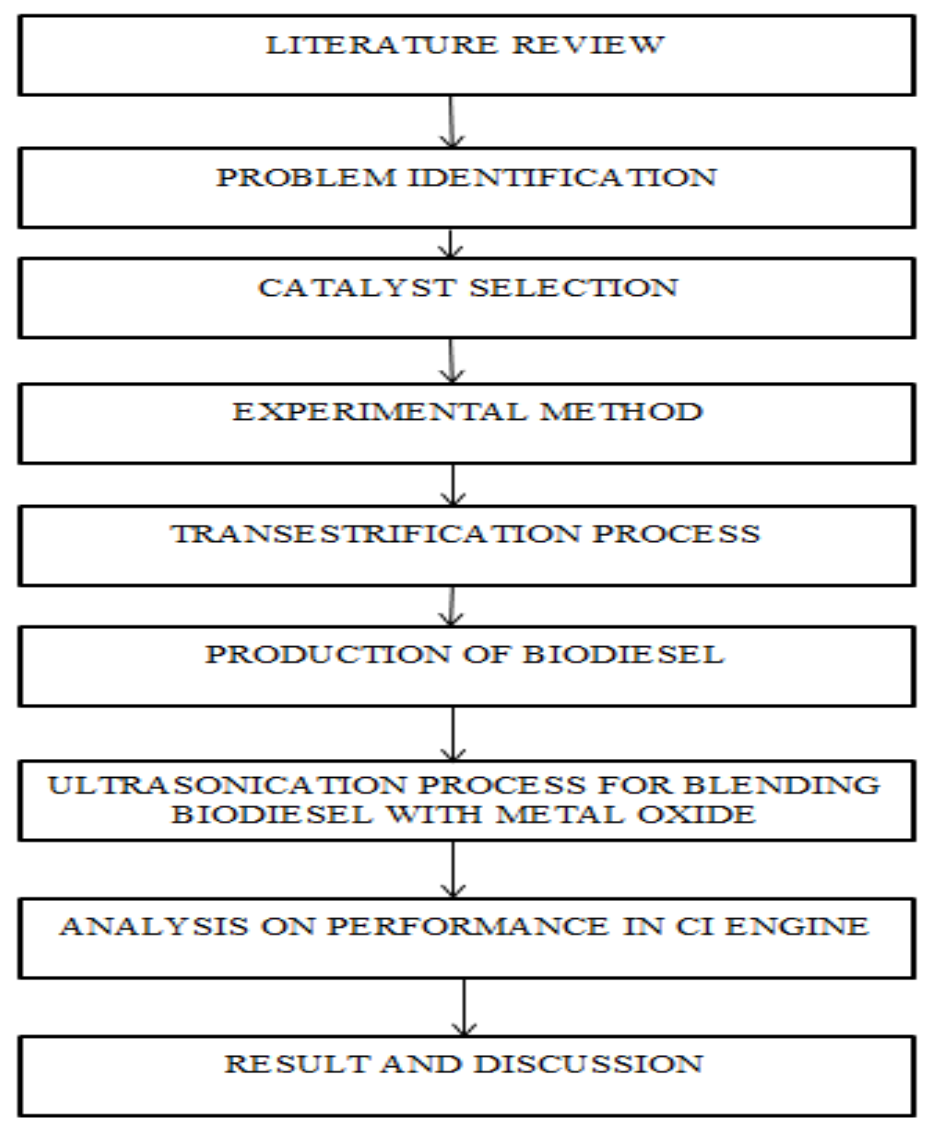

Fig 1:- Methodology 


\section{Problem Identification:-}

Biodiesel has become more attractive recently because of its environmental benefits and it is derived from renewable resources, bio degradeable and nontoxic in nature. Several biodiesel production method have been developed, among which tranestrification using alkali catalyst gives high level conversion triglycerids to their corresponding methyl ester in short reaction time.the process of tranestrification affected by the reaction condition, molar ratio alchol to oil,type of alchol,type and amount of catalyst,reaction time and temperature,purity of reactants free fatty acid and water contents of oil or fats.the efficiency of the $\mathrm{CI}$ engine performance is minimum in typical fuel. That means to make efficient fuel of blending metal oxide in fuel: Development of biodiesel oil, Environmental consideration, Economics aspects and advantages, Resources available of pungamia oil

\section{Experimental Setup:-}

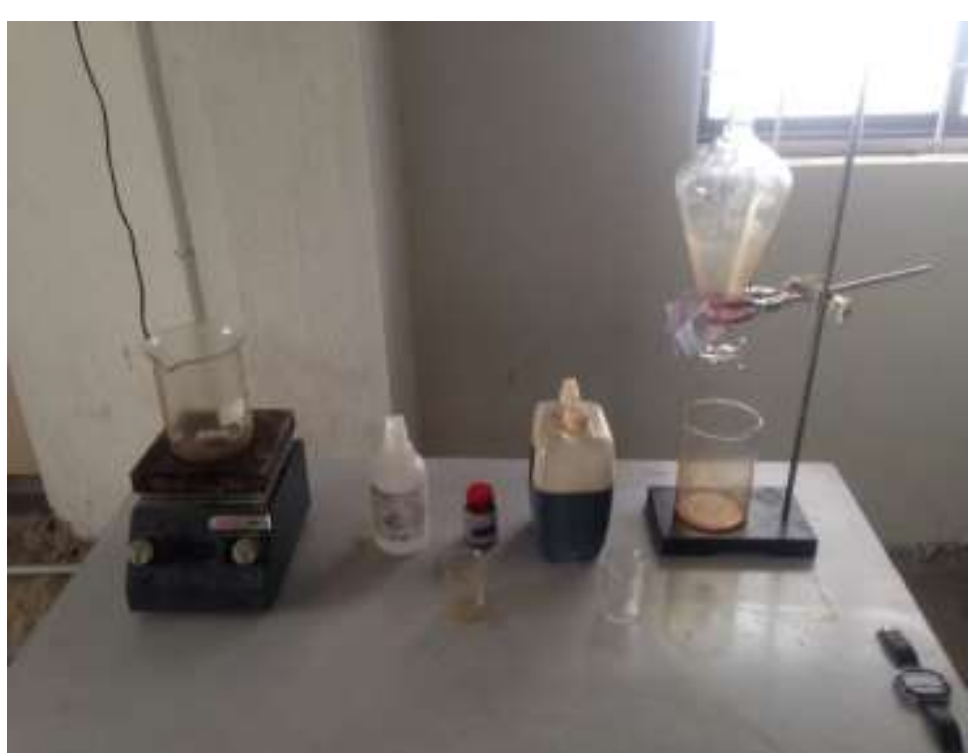

Fig 2:- Experimental setup for tranesetrification process

Reaction or tranestrification was carried out in a system. Reactor consisted of spherical flask, which was put inside the heat jacket.oil was used as medium of heat transfer from heat jacket to the reactor.thermostat was a part of heat jacket, which maintained the temperature of oil and in turns the temperature oof the reactants at a desired value. The reaction was carried out at around $50-90^{\circ} \mathrm{c}$.sperical flask consisted of openings the center one was used for putting stirrer in the reactor. Figure 2 shows that expiremental setup for tranesetrification process

\section{Experimental procedure:-}

A known quantity of karanja oil $\left(400 \mathrm{ml}\right.$ for each run) was taken inside the reactor and heated at above $70{ }^{0}$ c.this temperature was maintained throughout the reaction by the thermostat inside the heat jacket. Preheating was used to remove unwanted moisture present the oil. Figure 3 shows that process of magnetic stirring for pungamia oil Figure 3,4 and 5 show that the process of biodiesel. The transestrification was carried out in basic medium and to achieve it,tpa was used to catalyst. Catalyst was dissolved in alcohol $(\mathrm{meoh})=$. Once the oil temperature reached $50-90^{\circ} \mathrm{c}$, alcohol solution (containing dissolved catalyst) was added to the reactor and an equilibrium temperature was maintained. During the reaction alcohol gets vaporized.to prevent any reactant loss condenser was used to condense the alcohol vapour and reflux it back into reactor.condensor was also helpful in maintaining atmospheric pressure inside the reactor.once reaction was over the products were taken out through the outlet in the lower side of the reactor and put in the separating funnel.two phase (having different density) are formed as a result of transetrification.seperation was done using a separating funnel (separation took around two hours).upper layer consisted of biodiesel, alcohol, and some soap (formed as a result of side reaction saponication - free fatty acids get converted to soap).lower layer consisted of glycerine,excess alcohol,catalyst,impurities, and traces of unreacted oil. Figure 6 shows that experimental process. 


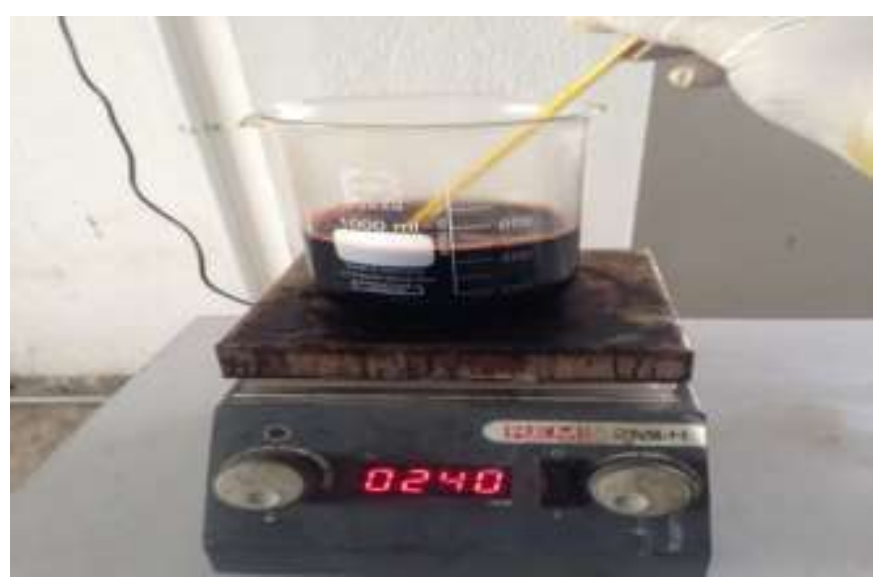

Fig 3:- Process of Magnetic stirring for Pungamia oil

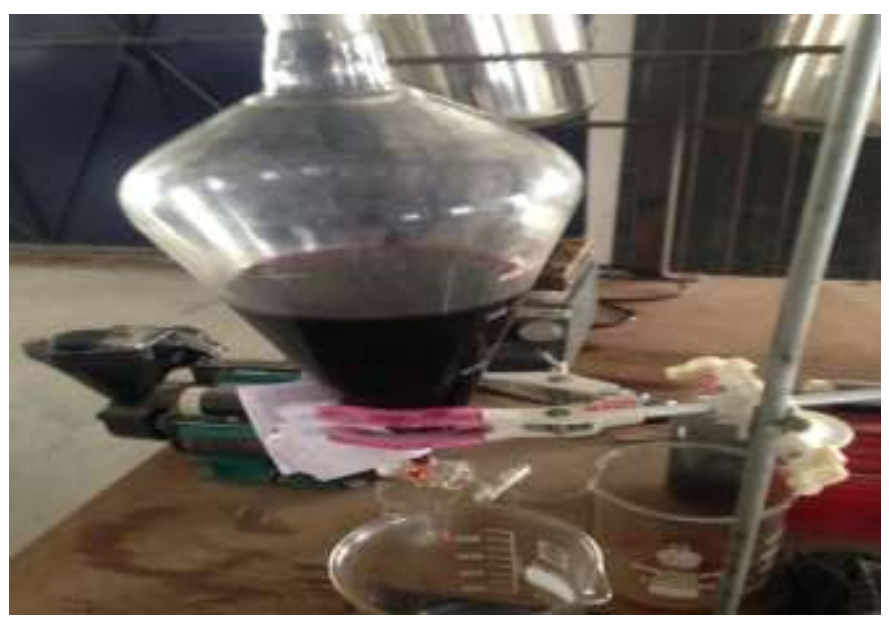

Fig 4:- Separation process of Pungamia oil

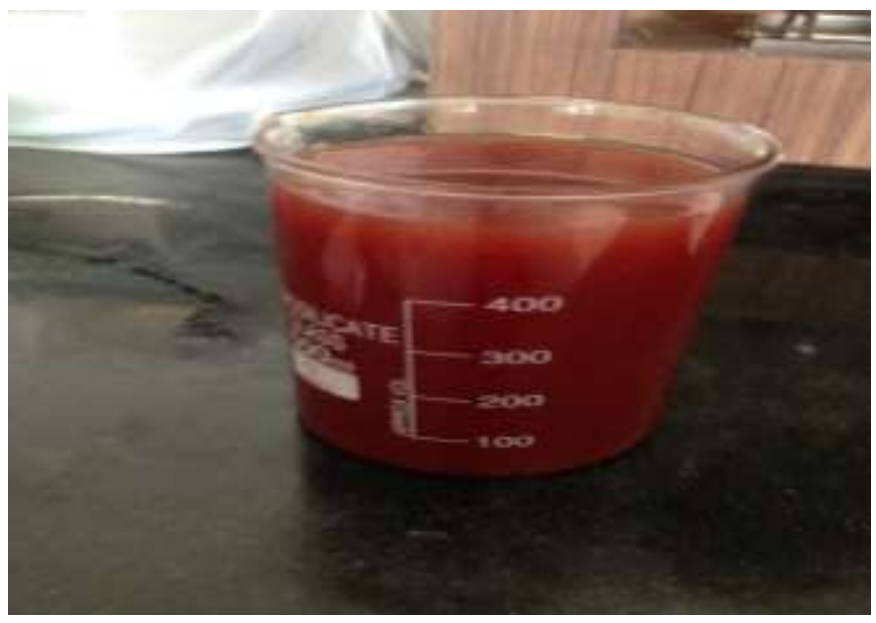

Fig 5:- Biodiesel (Pungamia Oil) after the Transestrification Process 


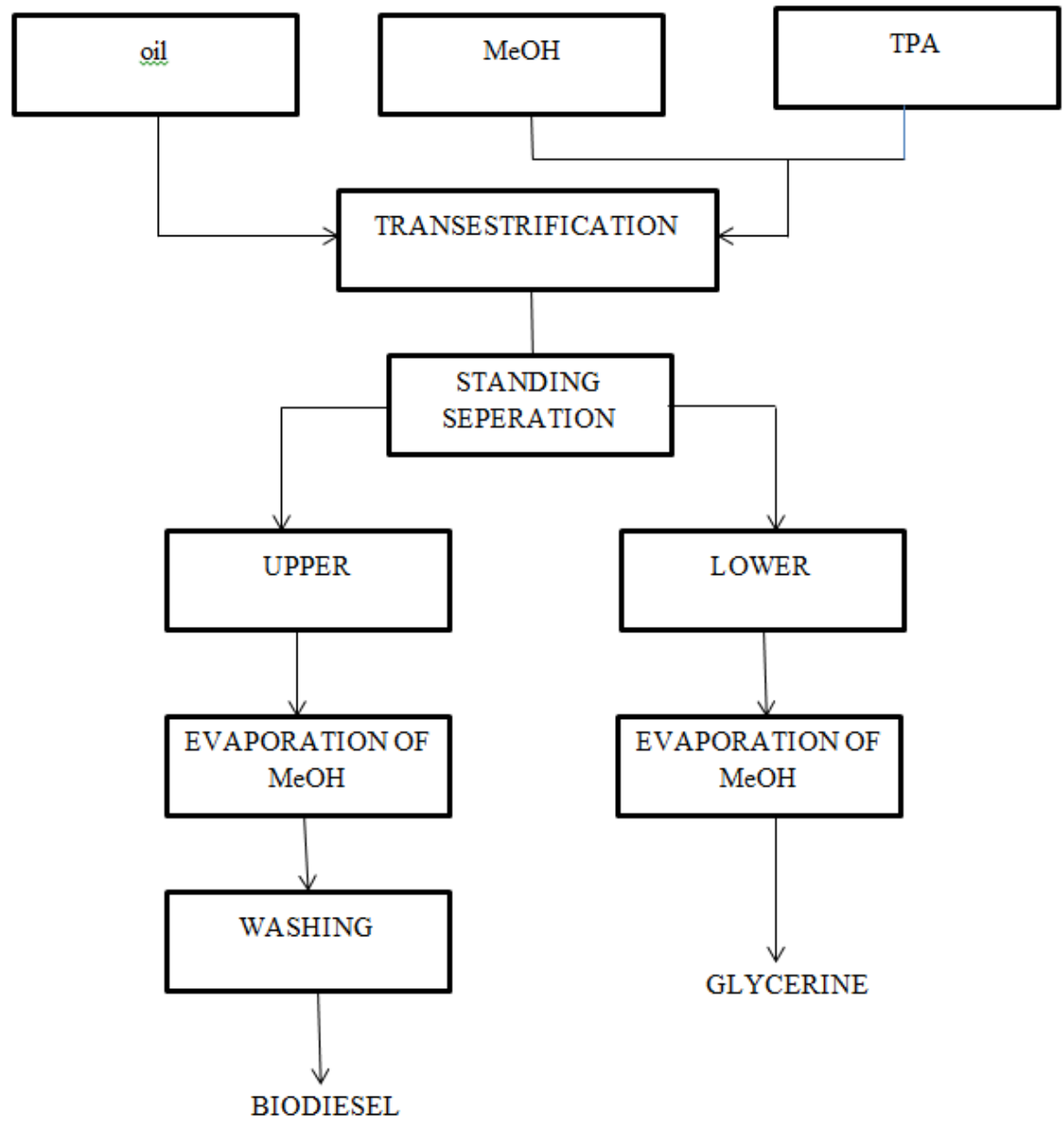

Fig 6:- Experimental process

\section{Results and Discussion:-}

Design of Experiment for the optimization of transesterification of pungamia oil

The design of experiment used a statistical technique to investigate the effects of various parameters included in experimental study and to determine their optimal combination. The design of experiment via the Taguchi method uses a set of orthogonal arrays for performing of the few experiments. That is, the Taguchi method involves the determination of a large number of experimental situations, described as orthogonal arrays, to reduce errors and enhance the efficiency and reproducibility of the experiments. Orthogonal arrays are a set of tables of numbers, which can be used to efficiently accomplish optimal experimental designs by considering a number of experimental situations

Table 1:- Orthogonal array used to design experiments with four parameters at three-levels L9

\begin{tabular}{|l|l|l|l|l|}
\hline $\mathrm{L}_{9}\left(3^{4}\right)$ & A & B & C & D \\
\hline 1 & 1 & 1 & 1 & 1 \\
\hline 2 & 1 & 2 & 2 & 2 \\
\hline 3 & 1 & 3 & 3 & 3 \\
\hline 4 & 2 & 1 & 2 & 3 \\
\hline 5 & 2 & 2 & 3 & 1 \\
\hline 6 & 2 & 3 & 1 & 2 \\
\hline 7 & 3 & 1 & 3 & 2 \\
\hline 8 & 3 & 2 & 1 & 3 \\
\hline 9 & 3 & 3 & 2 & 1 \\
\hline
\end{tabular}


In this study, Minitab-17, which is software for the Automatic Design and Analysis of Taguchi Experiments, was used to analyse the results and optimize the experiment conditions for setting the control variables. An experimental design methodology adopting the Taguchi approach was employed in this study, with the orthogonal array design used to screen the effects of four parameters(were shows in table 2) including the oil to alcohol molar ratio, catalyst type, catalyst concentration and reaction time, on the production of pungamia oil methyl esters. The diversity of factors was studied by crossing the orthogonal array of the control parameters

Table 2:- levels and factors arrangements for Taguchi method

\begin{tabular}{|l|l|l|l|l|l|}
\hline levels & Factors & $\begin{array}{l}\text { Catalyst } \\
\text { concentration }(\mathrm{gm})\end{array}$ & Oil to molar ratio & Temperature $\left({ }^{\circ} \mathrm{c}\right)$ & Reaction time $(\mathrm{min})$ \\
\hline 1 & 0.5 & $5: 1$ & 50 & 30 \\
\hline 2 & 1 & $10: 1$ & 70 & 60 \\
\hline 3 & 1.5 & $15: 1$ & 90 & 90 \\
\hline
\end{tabular}

Table 3:- Yields of Pungamia oil methyl ester

\begin{tabular}{|l|l|l|l|l|l|}
\hline Run & Catalyst $(\mathrm{gm})$ & $\begin{array}{l}\text { Oil to molar } \\
\text { ratio }\end{array}$ & Temperature $\left({ }^{\mathrm{o}} \mathrm{c}\right)$ & Time $(\mathrm{min})$ & Mean Yield (\%) \\
\hline 1 & 0.5 & $5: 1$ & 50 & 30 & 83 \\
\hline 2 & 0.5 & $5: 1$ & 70 & 60 & 87 \\
\hline 3 & 0.5 & $5: 1$ & 90 & 90 & 91 \\
\hline 4 & 1 & $10: 1$ & 70 & 90 & 90 \\
\hline 5 & 1 & $10: 1$ & 90 & 30 & 88 \\
\hline 6 & 1 & $10: 1$ & 50 & 60 & 89 \\
\hline 7 & 1.5 & $15: 1$ & 90 & 60 & 91 \\
\hline 8 & 1.5 & $15: 1$ & 50 & 90 & 91 \\
\hline 9 & 1.5 & $15: 1$ & 70 & 30 & 89 \\
\hline
\end{tabular}

Determination of Optimal Experimental Condition by Design of Experiment:-

The yields of pungamia oil methyl ester determine in table 3 were prepared under nine sets of experimental conditions. From these results, which had a mean yield of pungamia oil methyl ester of $91 \%$, appeared to have the set experiment conditions with optimal parameters. The lowest yield of pungamia oil methyl ester, at $83 \%$. However, it is likely that this would not be a preferred way of selecting the optimal conditions using the Taguchi method for the design of an experiment. Where $n$ is the number of repetitions of each experiment and Yi the yield of pungamia oil methyl ester. Table 4 shows that SN Ratio of pungamia oil methyl ester.

According to the analysis for the case of 'larger-the-better', the $\mathrm{S} / \mathrm{N}$ ratio was assessed using the following equation

$$
\frac{\mathrm{S}}{\mathrm{N}} \text { ratio }=-10 \log \left(\frac{1}{\mathrm{n}} \sum_{\mathrm{i}=0}^{\mathrm{n}}\left(\frac{1}{\mathrm{yi}}\right)^{2}\right)
$$

Example calculation for S/N RATIO $-10 \log (1 / 1)(1 / 91)^{2}=39.18$

Table 4:- Yields of Pungamia oil methyl ester and $\mathrm{S} / \mathrm{N}$ ratios for the nine sets of experiments

\begin{tabular}{|l|l|l|l|l|l|l|}
\hline Ex.no & Catalyst & $\begin{array}{l}\text { Oil to molar } \\
\text { ratio }\end{array}$ & Reaction time & Temperature & yield & SN ratio \\
\hline 1 & 0.5 & $5: 1$ & 50 & 30 & 83 & 38.3816 \\
\hline 2 & 0.5 & $5: 1$ & 70 & 60 & 87 & 38.7904 \\
\hline 3 & 0.5 & $5: 1$ & 90 & 90 & 91 & 39.0849 \\
\hline 4 & 1 & $10: 1$ & 70 & 90 & 90 & 39.0849 \\
\hline 5 & 1 & $10: 1$ & 90 & 30 & 88 & 38.8897 \\
\hline 6 & 1 & $10: 1$ & 50 & 60 & 89 & 38.9878 \\
\hline 7 & 1.5 & $15: 1$ & 90 & 60 & 91 & 39.1808 \\
\hline 8 & 1.5 & $15: 1$ & 50 & 90 & 91 & 39.1808 \\
\hline 9 & 1.5 & $15: 1$ & 70 & 30 & 89 & 38.9878 \\
\hline
\end{tabular}


Generally, a process to be optimized has several control factors which directly decide the target or desired value of the end product. The optimization then involves determining the best control factor levels so that the output is at the target value. A signal-to-noise $(\mathrm{S} / \mathrm{N})$ ratio is a performance measure, which calculates the effect of the noise factors on the quality characteristic. These $\mathrm{S} / \mathrm{N}$ ratios are offered to offer a product design that simultaneously places the response to a target and a minimum variance. The $\mathrm{S} / \mathrm{N}$ ratios are different in terms of their characteristics, of which there are generally three types, i.e. smaller-the-better, larger-the-better and nominal-the-best. The $\mathrm{S} / \mathrm{N}$ ratios for the nine sets of experiments. The mean yield of pungamia oil methyl ester and the $\mathrm{S} / \mathrm{N}$ ratio were $91 \%$ and 39.18 , respectively. The highest mean yield of pungamia oil methyl ester. The relationship between the yield of pungamia oil methyl ester and the $\mathrm{S} / \mathrm{N}$ ratio was also similarly observed in other experiments. The mean $\mathrm{S} / \mathrm{N}$ ratio, which was calculated from the gist of the parameters and the interactions at assigned levels, was the average of all the $\mathrm{S} / \mathrm{N}$ ratios of a set of control parameters at a given point. The distributions for the four influential parameters are summarized .The contribution of an experimental parameter was calculated from the maximum difference in the values between the mean $\mathrm{S} / \mathrm{N}$ ratios at each stage. The order of influence of the parameters in terms of the yield of rapeseed methyl ester was: I (catalyst concentration) and II (reaction time). In order to more systematically perform an analysis of the relative importance of each parameter, an analysis of variance (ANOVA) was used to optimize the results obtained using Taguchi method. This provided information on the relative influence of parameters and their interactions with respect to the various results. According to the ANOVA results and regression equation plotted below.

Table 5:- Optimum conditions for settling the control parameters and their contributions

\begin{tabular}{|l|l|l|l|l|l|l|l|}
\hline TERM & DOF & Seq.SS & Adj.SS & Adj.MS & F & P & \% of contribution \\
\hline CATALYST & 2 & 16.89 & 8.444 & 8.444 & 1.38 & 0.321 & 31.53826 \\
\hline OIL TO MOLAR RATIO & 2 & 4.222 & 2.111 & 2.111 & 0.26 & 0.782 & 7.883631 \\
\hline TEMPERATURE & 2 & 8.222 & 4.111 & 4.111 & 0.54 & 0.607 & 15.35273 \\
\hline TIME & 2 & 23.00 & 11.50 & 11.50 & 2.48 & 0.164 & 43.39538 \\
\hline ERROR & 16 & 01.22 & 0.0762 & & & & 2.27 \\
\hline TOTAL & 24 & 53.554 & & & & & 100 \\
\hline
\end{tabular}

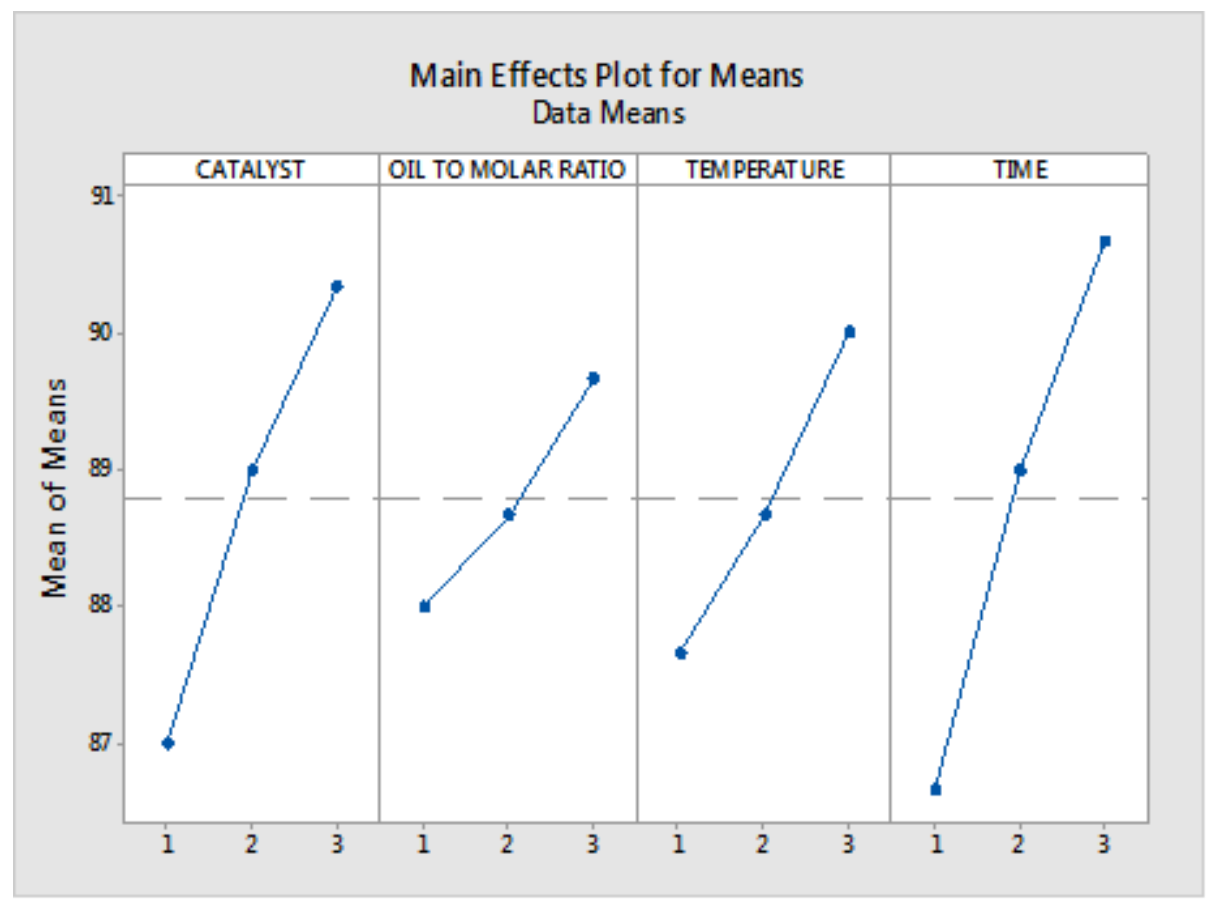

Fig 7:- Main effect of means 


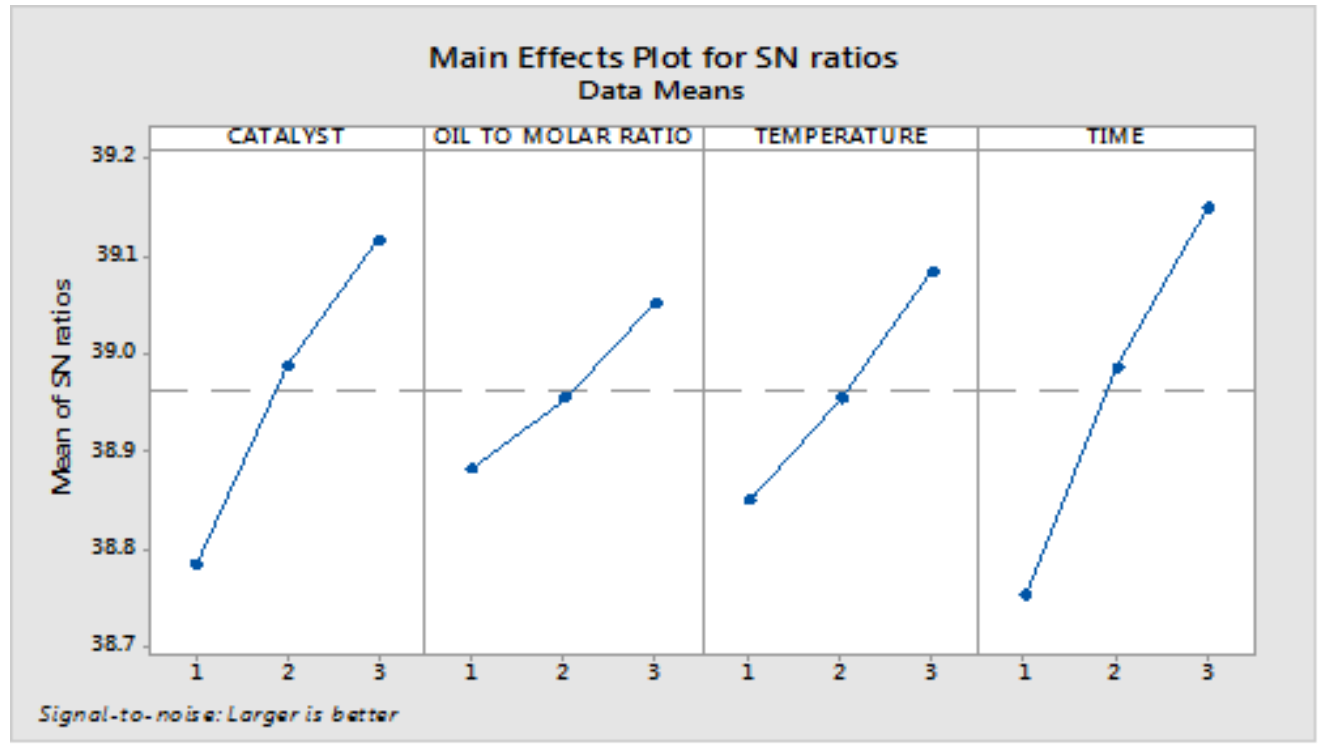

Fig 8 Main Effect Plot for SN Ratios

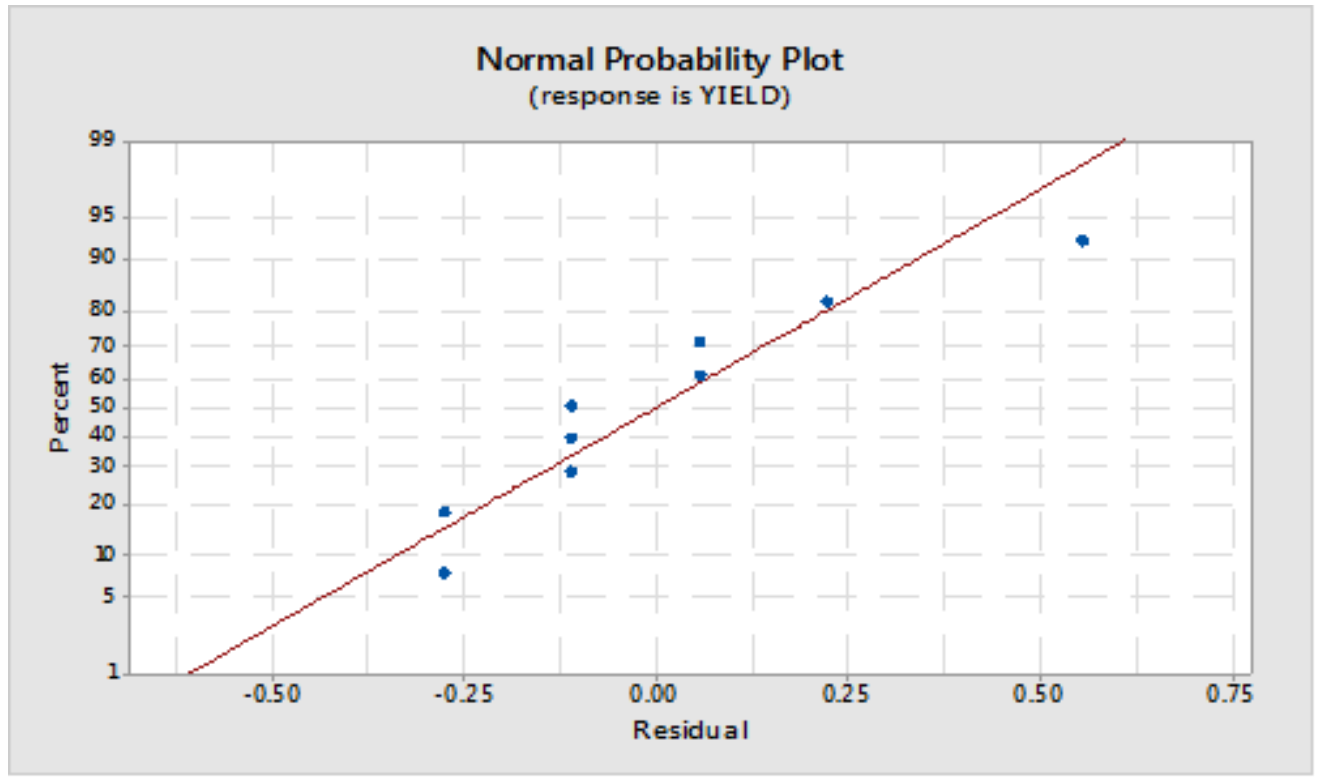

Fig 9:- Normal probability plot

\section{Regression Equation:-}

Yield $=77.444+1.667$ Catalyst +0.833 Oil to Molar ratio +1.167 Temperature +2.000 Time

$\mathrm{S}=0.971825 \quad \mathrm{R}-\mathrm{Sq}=96.2 \% \quad \mathrm{R}-\mathrm{Sq}(\operatorname{adj})=95.9 \%$

The goodness of fit was clarified by the determination coefficient $\left(\mathrm{R}^{2}\right)$.In this study, the value of determination coefficient is 0.962 which is indicated that $4.8 \%$ of the total variations were not explained by the regression model. The adjusted determination coefficient is 0.959 . So we noticed that the adjusted determination coefficient is closer to the determination coefficient which means a good correlation between the responses and the experimental results in response as yield. 


\section{Conclusion:-}

The study has enabled us to confirm that karanja oil can be used as a raw material to obtain biodiesel which can be used as fuel in diesel engine. The engine performance with biodiesel is similar to that of diesel, while emission are less in case of biodiesel. There are two aspects of the cost of biodiesel (i) cost of raw material (vegetable oil) and (ii) cost of processing. The cost of raw material (vegetable oil) accounts to $60-70$ percent of the cost of biodiesel fuel using non-edible oil like karanja oil (in place of vegetable oil) will surely improves the economics of the process (biodiesel production). The permutation of process parameters such as Catalyst and time have greatest contribution on response. The percentage of contribution of catalyst and time on yield is $32 \%$ and $42 \%$ respectively. The process parameters for accomplishing the desired response can be obtained from the mathematical model. The percentage of errors is obtained between the predicted results and the experimental results. Errors are normally distributed which is indicated by Normal Probability plot and has been found that the deviation is well within the limit of $\mathbf{9 5 \%}$ confidence level. Confirmatory test has been conducted to ensure the validity of the model and the error is within 5\%. It can be noted that increasing the methanol-oil ratio from 5:1 wt $\%$ to $15: 1 \mathrm{wt} \%$ had an insignificant effect on the yield. The normal probability plot graph is obtained in the form of straight line so the errors are distributed normally.

\section{References:-}

1. Arul Mozhi Selvan V, Anand Rb, Udayakumar M, "Effects Of Cerium Oxide Nanoparticle Addition In Diesel And Diesel-Biodiesel- Ethanol Blends On The Performance And Emission Characteristics Of A CI Engine" Arpn J Eng Appl Sci ,2009,4:16.

2. V. Arul Mozhi Selvan, R.B.Anand, M.Udayakumar, Fuel, 2014, 130 (1), 160-167.

3. Karthikeyan, Performance And Emission Study On Zinc Oxide Nano Particle Addition With Pomolion Stearin Wax Biodiesel Of CI Engine, J. Sci. Ind. Res. 73 (2014).

4. Karthikeyan, An Environmental Effect Of Gso Methyl Ester With Zno Additive Fuelled Marine Engine, Ind. J. Geo-Mar. Sci. 43 (4) (2014).

5. M.A.Lenin, M.R.Swaminathan, G.Kumaresan, Fuel, 2013, 109 (1), 362-365.

6. Metin Guru, Atilla Koca, Ozer Can, Can Cinar, Fatih Sahin, "Biodiesel Production From Waste Chicken Fat Based Sources And Evaluation With Mg Based Additive In A Diesel Engine", Renewable Energy 35 (2010) 637-643.

7. Mu-Jung Kao, Chen-Ching Ting, Bai-Fu Lin, Tsing-Tshih Tsung, Journal of Testing And Evaluation, 2007, 36 (2), 1-8.

8. Rolvin D'silva, Binu K.G, Thirumaleshwara Bhat, International Conference On Materials Processing And Characterization, 2015, 2 (1), 3728-3735

9. Rakhi N.Mehta, Mousumi Chakraborty, Parimal A.Parikh, Fuel , 2014, 120 (1), 91-97.

10. R. Sathiyamoorthi*, M. Puviyarasan, B. Bhuvanesh Kumar And D. Breslin Joshua "Effect of Ceo2 Nano Additive On Performance And Emission Characteristics Of Diesel Engine Fuelled By Neem Oil-Biodiesel" Chem. Sci.: 14(S2), 2016, 473-484.

11. J.Sadhik Basha, R.B.Anand, Alexandria Engineering Journal, 2014, 53 (1), 259-273.

12. Sajith V, Sobhan $\mathrm{Cb}$, Peterson $\mathrm{Gp}$, "Experimental Investigations On The Effects Of Cerium Oxide Nanoparticle Fuel Additives On Biodiesel”, Adv Mech Eng. 2010, Doi:10.1155/2010/581407.

13. A.Selvaganapthy, A.Sundar, B.Kumaraguruban, P.Gopal, Arpn J.Sci Technol. 2013, 3 (1), 112-115.

14. A.Selvaganapthy, A.Sundar, B.Kumaragurubaran, P.Gopal, "An Experimental Investigation To Study The Effects Of Various Nano Particles With Diesel On Di Diesel Engine", Arpn Journal Of Science And Technology, Vol. 3, No. 1, January 2013, Issn 2225-7217.

15. M. B. Shafii, F. Daneshvar, N. Jahani, And K.Mobini, Advances In Mechanical Engineering, 2011, 3 (1), 1-5.

16. T. Senthil Kumar, P. Senthil Kumar, K. Annamalai "Experimental Study On The Performance And Emission Measures Of Direct Injection Diesel Engine With Kapok Methyl Ester And Its Blends", Renewable Energy 74 (2015) 903-909.

17. Shafii Mb, Deneshvar F, Jahani N, Mobini K, "Effect Of Ferrofluid On The Performance And Emission Patterns Of A Four Stroke Diesel Engine”, Adv Mech Eng. 2011, Doi:10.1155/2011/529049. 